\title{
A VALORIZAÇÃO DO PROFISSIONAL DOCENTE NO INSTITUTO FEDERAL DE SÃO PAULO: ASPECTOS NORMATIVOS DA POLÍTICA INSTITUCIONAL
}

\author{
THE VALUATION OF THE PROFESSIONAL EDUCATOR IN \\ THE FEDERAL INSTITUTE OF SÃO PAULO: NORMATIVE \\ ASPECTS OF INSTITUTIONAL POLICY
}

\section{LA VALORACIÓN DEL PROFESIONAL DOCENTE EN EL INSTITUTO FEDERAL DE SÃO PAULO: ASPECTOS NORMATIVOS DE LA POLÍTICA INSTITUCIONAL}

\author{
Marcelo Velloso Heeren ${ }^{1}$ \\ https://orcid.org/0000-0002-5625-7652
}

${ }^{1}$ Instituto Federal de São Paulo, Catanduva, São Paulo - Brasil. E-mail: marceloheeren @ gmail.com.

\section{Resumo}

O objetivo do presente trabalho foi analisar como o Instituto Federal do Estado de São Paulo (IFSP) se estrutura no sentido de organizar uma política institucional de valorização do profissional docente. A pesquisa de abordagem qualitativa em Educação possui destaque para a análise documental dos textos normativos do IFSP. A valorização do docente pode ser verificada a partir da existência de um plano de carreira que permite sua progressão e promoção funcional em razão das atividades desenvolvidas e, também, pela sua capacitação educacional, favorecendo os proventos mensais, além de basear a contratação por meio de concurso público. Outro aspecto importante é a institucionalização de uma política de capacitação e qualificação docente que possibilite a cada indivíduo utilizar parte de sua carga horária de trabalho semanal para a realização de cursos e o afastamento total ou parcial das atividades para a efetuação de cursos de pós-graduação stricto sensu. Além disso, a organização das atividades docentes proporciona um trabalho que valoriza as ações relacionadas com o ensino, a pesquisa e a extensão. Pode-se verificar que o IFSP possui uma política institucional que valoriza o profissional docente em relação aos diversos aspectos da sua realidade profissional.

Palavras-chave: Instituto Federal de São Paulo. Docente. Valorização Profissional. Educação Profissional. 


\begin{abstract}
The aim of the present study was to present how the Federal Institute of the State of São Paulo (IFSP) is structured in order to organize an institutional policy of valorization of the professional educator. The research of qualitative approach in education has emphasis on the documentary analysis of the normative texts of the IFSP. The valorization of the teacher can be verified from the existence of a career plan that allows its progression and functional promotion due to the developed activities and also for its educational qualification, favoring the monthly salaries, besides basing the hiring through tenurial. Another important aspect is the institutionalization of a teacher training and qualification policy, which enables each individual to use part of his/her weekly workload for courses and also offers a total or partial absence from activities for graduate school courses (stricto sensu). In addition, the organization of teaching activities provides work that values actions related to teaching, research and extension. It can be seen that the IFSP has an institutional policy that values the professional educator in relation to the various aspects of their professional reality.
\end{abstract}

Keywords: Federal Institute of São Paulo. Educator. Professional Appreciation. Professional Education.

\title{
Resumen
}

El objetivo del presente trabajo fue analizar cómo se estructura el Instituto Federal del Estado de São Paulo (IFSP) para organizar una política institucional de valorización del profesional docente. La investigación de enfoque cualitativo en Educación tiene énfasis en el análisis documental de los textos normativos del IFSP. La valorización del docente puede verificarse a partir de la existencia de un plan de carrera que permite su progresión y promoción funcional debido a las actividades desarrolladas y, también, por su calificación educativa, favoreciendo los sueldos mensuales, además de basar la contratación a través de concurso público. Otro aspecto importante es la institucionalización de una política de capacitación y calificación docente que le haga posible a cada individuo usar parte de su carga de trabajo semanal para hacer cursos y la ausencia total o parcial de las actividades para cursos de posgrado stricto sensu. Además, la organización de actividades docentes proporciona un trabajo que valora las acciones relacionadas con la enseñanza, la investigación y la extensión. Se puede ver que el IFSP tiene una política institucional que valora al profesional docente en cuanto a los diversos aspectos de su realidad profesional.

Palabras clave: Instituto Federal de São Paulo. Docente. Valoración Professional. Educación Profesional.

\section{Introdução}

A valorização do profissional docente, bem como a sua formação, seja ela inicial e/ou continuada, configura-se atualmente em um importante espaço de reflexão acadêmica no sentido de elaborar quais são as necessidades de formação para o professor do ensino básico no Brasil diante dos desafios sociais, culturais, políticos e econômicos impostos nas diferentes regiões e localidades do país. Considerados também um dos fatores que 
influenciam a qualidade da educação (PERES et al., 2013), os docentes são constantemente culpabilizados pelos resultados ruins dos estudantes observados nas avaliações de larga escala, como Prova Brasil, Exame Nacional do Ensino Médio (ENEM) e Programme for International Student Assessment (PISA). Diante desse cenário, muitos estudos e políticas públicas têm sido organizados para contribuir com os processos que valorizam o docente e colaboram para a melhoria da formação inicial e continuada dos professores da educação básica no Brasil. O Plano Nacional de Educação (2014-2024) apresenta esse direcionamento e dedica cinco das 20 metas para esse tema em indicações que preveem a formação inicial, a formação continuada, a valorização profissional e o plano de carreira (BRASIL, 2014).

A valorização dos profissionais que atuam na educação nacional, por sua vez, já está prevista na Carta Constitucional de 1988, apresentando-se, no artigo $\mathrm{n}^{\circ}$ 206, como um princípio do ensino a "valorização dos profissionais da educação escolar, garantidos, na forma da lei, planos de carreira, com ingresso exclusivamente por concurso público de provas e títulos, aos das redes públicas" (BRASIL, 1988). Complementarmente, a Lei de Diretrizes e Bases da Educação Nacional (LDB) (BRASIL, 1996) define essa valorização como um princípio a ser seguido no ensino nacional, estabelecendo ações a serem promovidas pelos diferentes sistemas de ensino:

Art. $67^{\circ}$. Os sistemas de ensino promoverão a valorização dos profissionais da educação, assegurando-lhes, inclusive nos termos dos estatutos e dos planos de carreira do magistério público:

I - Ingresso exclusivamente por concurso público de provas e títulos;

II - Aperfeiçoamento profissional continuado, inclusive com licenciamento periódico remunerado para esse fim;

III - Piso salarial profissional;

IV - Progressão funcional baseada na titulação ou habilitação, e na avaliação do desempenho;

V - Período reservado a estudos, planejamento e avaliação, incluído na carga de trabalho;

V I- Condições adequadas de trabalho (BRASIL, 1996).

Diante desse conjunto de normas que orientam nacionalmente a Educação, especificamente em relação a essa temática de valorização do profissional docente, é necessário que possamos identificar de que forma cada sistema de ensino, seja federal, municipal ou estadual, está organizado para permitir que tal prerrogativa constitucional possa 
HEEREN, M. V.

ser observada efetivamente na prática educacional de cada sistema ou instituição de ensino. Essa temática se apresenta particularmente importante quando o universo de análise se relaciona com a educação profissional e tecnológica, sobretudo em um recorte específico do Instituto Federal de Educação do Estado de São Paulo (IFSP).

Criados a partir da aprovação da Lei $\mathrm{n}^{\circ} 11.892$, de 29 de dezembro de 2008, os Institutos Federais de Educação se caracterizam por serem um conjunto de instituições especializadas na oferta de educação profissional e tecnológica nas diferentes modalidades de ensino, quais sejam, ensino básico, técnico ou superior. Nesse contexto, a formação docente para atuar na educação profissional e tecnológica (EPT) tem sido tema de debates constantes na área acadêmica e também nos espaços reflexivos da prática profissional, suscitando questionamentos importantes sobre os saberes profissionais específicos da EPT e qual modelo de formação seria adequado para esse profissional (CARVALHO e SOUZA, 2014). É importante considerarmos que as políticas públicas de Educação devem estabelecer um conjunto normativo coerente com as indicações constitucionais, promovendo a elaboração de programas, projetos e outras ações que contemplem o arcabouço social e político bastante diverso do país, guardando as adequadas condições para a garantia desses princípios no cotidiano escolar dos estudantes. Sendo assim, é necessário que as políticas de cada unidade dos Institutos Federais, independente do segmento da escola ao qual esteja relacionada, consiga deixar evidente a relação entre as normativas da rede federal e as específicas de cada instituição com as prerrogativas constitucionais previstas no artigo ${ }^{\circ} 206$ da CF/88.

Dessa forma, o objetivo da presente pesquisa foi apresentar, a partir das indicações previstas na Constituição de 1988 e na LDB de 1996 sobre o tema valorização profissional docente, como o Instituto Federal de São Paulo estrutura suas normativas no sentido de organizar uma política institucional de valorização do profissional docente. $\mathrm{O}$ trabalho se constitui em uma pesquisa de abordagem qualitativa em Educação, com destaque para a utilização da pesquisa e a análise documental, que se complementam para viabilizar os objetivos do trabalho. A pesquisa documental, de cunho legal/normativo, orientou-se pela necessidade de definir conteúdos que pudessem contribuir para um entendimento sobre a relação entre a política educacional do IFSP e a garantia das indicações previstas na CF e na LDB em relação à valorização docente. Nesse contexto, definiram-se a Constituição Federal de 1988; a Lei de Diretrizes e Bases da Educação, Lei nº 9.394/96; o Plano Nacional de Educação, Lei n 13.005/14; a Lei de Criação dos Institutos Federais, Lei $n^{\circ}$ 11.892/08; a 
Resolução CNE/CEB n 6/12, além das normativas específicas do IFSP compreendidas no espaço de tempo entre 2008 e 2019.

\section{Valorização do profissional docente no Instituto Federal de São}

\section{Paulo}

Conforme discriminado no artigo $n^{\circ} 67$ da LDB, as ações indicadas para promover a valorização do profissional docente compreendem um conjunto de elementos que se relacionam com aspectos amplos e vinculados direta e indiretamente ao cotidiano do docente na instituição de ensino, situação que se traduz também sobre a qualidade da estruturação e o desenvolvimento do processo de ensino e aprendizagem do estudante. Nesse contexto, o estabelecimento de diretrizes e políticas específicas que englobem os diversos aspectos da carreira docente, normatizando desde o ingresso até sua progressão funcional, bem como os aspectos vinculados à remuneração, as possibilidades de aperfeiçoamento e qualificação profissional e a existência de condições adequadas para a organização do trabalho docente (SAVIANI, 2009) se colocam como condição necessária a toda instituição e/ou sistema de ensino que de fato estejam engajados com o desenvolvimento de uma educação que não se reduza à simples reprodução de conhecimentos e informações produzidas historicamente pela sociedade.

Adicionalmente, quando abordamos especificamente a formação docente, é importante considerarmos que ela deve promover a formação e a atividade docente voltada para a pesquisa e reflexão da sua prática, sendo necessária a criação dos espaços institucionais estruturais e temporais que possibilitem essa realização, valorizando a relevância dos processos de estudo contínuo do docente em seu cotidiano de trabalho. Esse contexto institucional coincide com as informações apresentadas pela Organização das Nações Unidas para a Educação, a Ciência e a Cultura (Unesco) do ano de 2004 no texto "O perfil do professor brasileiro: o que pensam, o que fazem, o que almejam", no qual se mostra que os professores brasileiros "não possuem o hábito de estudar", pois são formados por instituições instrucionistas e que valorizam as aspectos reprodutivos nas práticas cotidianas (DEMO, 2010). Observam-se esses dados com grande preocupação, pois uma atividade de caráter intelectual e reflexivo é reduzida a algo puramente técnico e instrumental.

A partir do exposto, pode-se vislumbrar a importância de se constituir uma instituição 
HEEREN, M. V.

e/ou sistema de ensino que dialogue política e normativamente com o entendimento no qual a valorização docente, considerando seus aspectos mais amplos, seja um parâmetro para a criação e condução da política educacional. Será apresentado na sequência do presente trabalho como é desenvolvida a política de valorização do profissional docente no Instituto Federal de São Paulo, especificamente em relação aos critérios apresentados anteriormente e indicados no $\operatorname{artigo~n}^{\circ} 67$ da Lei de Diretrizes e Bases da Educação Nacional.

\subsection{Valorização da carreira docente}

O primeiro aspecto a ser evidenciado no início da carreira docente indica que o IFSP valoriza a contratação de um profissional que atenda a um conjunto de pré-requisitos necessários para sua adequada atuação educacional diante das especificidades institucionais. Apesar de legalmente o IFSP atender aos ditames normativos que orientam a contratação de professores apenas por concurso público de provas e títulos ${ }^{1}$, a instituição orienta, em seus concursos públicos, alguns critérios que priorizem o atendimento das demandas existentes em cada unidade educacional, sugerindo parâmetros para a elaboração das provas teóricas, práticas e de títulos conforme as necessidades institucionais, e não somente sob os indicativos de formação do docente, mas também em relação às especificidades pedagógicas da instituição.

Outro aspecto que indica uma valorização da carreira docente é a possibilidade de, após ingressar na instituição, o docente ter o valor do seu salário readequado, ajustando-o de acordo com a sua titulação acadêmica. O salário mensal de cada servidor é formado pela soma de dois componentes estabelecidos na Lei $\mathrm{n}^{\circ} 12.772 / 12$, que dispõe sobre a estruturação do Plano de Carreiras e Cargos de Magistério Federal, a saber: o vencimento básico (VB), referente ao cargo ocupado pelo servidor, e a retribuição por titulação (RT), concernente ao nível de formação (graduação, especialização, mestrado ou doutorado) atingido pelo servidor no início da carreira, sendo possível também sua alteração ao longo da trajetória docente (BRASIL, 2012b).

O servidor docente dos Institutos Federais de Educação Tecnológica, denominados na Lei $\mathrm{n}^{\circ}$ 12.772/12 como docente do Ensino Básico, Técnico e Tecnológico (EBTT), possui

\footnotetext{
${ }^{1}$ Para mais detalhes, consultar a Lei ${ }^{\circ} 11.740 / 08$, que dispõe sobre cargos criados pertencentes ao plano de carreira docente referentes ao magistério em âmbito federal, e a Lei ${ }^{\circ}$ 8.112/90, que normatiza o Estatuto dos Servidores Públicos Federais.
} 
uma carreira estabelecida em cinco classes verticais (DI, DII, DIII, DIV e professor titular) divididas em outros subníveis horizontais da seguinte forma: 1- classe DI- níveis I e II; 2 classe DII- níveis I e II; 3- classe DIII- níveis I, II, III e IV; 4- classe DIV- níveis I, II, III e IV. O desenvolvimento da carreira do docente do EBTT ocorrerá mediante progressão funcional e promoção ${ }^{2}$, devendo o servidor cumprir um interstício de 24 meses e ser aprovado em processo de avaliação de desempenho. Para atingir o cargo de professor titular, o docente deverá realizar outro concurso público constituído de provas escrita, oral e defesa de memorial, devendo o mesmo ter o título de doutor e, no mínimo, 10 anos de experiência na área de conhecimento exigida. Em razão de o docente entrar na instituição no nível mais baixo do plano de carreira (D1-I), a Lei $n^{\circ} 12.772 / 12$ permite que ele requisite sua aceleração para o nível correspondente à sua titulação após completar o período de três anos do estágio probatório pela apresentação de título de especialista ou de mestre ou doutor (BRASIL, 2012).

Ainda em relação ao desenvolvimento da carreira do docente do EBTT, a mesma lei prevê um instrumento normativo que possibilita a valorização das atividades docentes peculiares aos institutos federais, nas quais estão incluídas as ações de ensino, pesquisa e extensão, bem como a participação no cotidiano político-administrativo relacionados ao tripé institucional de ensino-pesquisa-extensão. $O$ artigo $n^{\circ} 18$ da lei propõe uma equivalência de titulação, com perspectiva de modificação de RT no salário, o que valoriza as atividades docentes peculiares exigidas com o reconhecimento de saberes e competências (RSC).

Art. 18. No caso dos ocupantes de cargos da Carreira de Magistério do Ensino Básico, Técnico e Tecnológico, para fins de percepção da RT, será considerada a equivalência da titulação exigida com o Reconhecimento de Saberes e Competências - RSC.

$\S 1^{\circ} \mathrm{O}$ RSC de que trata o caput poderá ser concedido pela respectiva IFE de lotação do servidor em 3 (três) níveis:

I - RSC-I;

II - RSC-II; e

III - RSC-III.

$\S 2^{\circ}$ A equivalência do RSC com a titulação acadêmica, exclusivamente para fins de percepção da RT, ocorrerá da seguinte forma:

I - diploma de graduação somado ao RSC-I equivalerá à titulação de especialização;

\footnotetext{
${ }^{2}$ A Lei $n^{\circ} 12.772 / 12$ definiu a progressão funcional como sendo a passagem do servidor para o nível de vencimento imediatamente superior dentro de uma mesma classe, e a promoção sendo a passagem do servidor de uma classe para outra subsequente.
} 
II - certificado de pós-graduação lato sensu somado ao RSCII equivalerá a mestrado; e

III - titulação de mestre somada ao RSC-III equivalerá a doutorado (BRASIL, 2012).

Para fins de validação do RSC, cada instituto federal, seguindo a Resolução $\mathrm{n}^{\circ}$ 1/14 da Secretaria de Educação Tecnológica (BRASIL, 2014a), ficou responsável pela elaboração de um regulamento que pudesse normatizar internamente a concessão desse reconhecimento. No Instituto Federal de São Paulo, o RSC foi regulamentado a partir da aprovação da Resolução $n^{\circ}$ 80/14 pelo Conselho Superior do IFSP (IFSP, 2014).

\subsection{Política de formação e qualificação profissional docente do IFSP}

Antes de abordarmos especificamente as normativas internas do IFSP sobre como contribuir para a formação docente, é importante buscarmos entender como esse tema está disposto na legislação nacional e por que se configura de grande relevância para a educação profissional e tecnológica. A necessidade de investimento na formação docente é um aspecto primordial na educação nacional e, por esse motivo, estão previstas, nas metas 15 e 16 do Plano Nacional de Educação (2014-2024), estratégias que incrementem a formação inicial e continuada desse profissional (BRASIL, 2014c). O investimento direto em ações que promovam a formação de professores para a EPT é decisivo para que a atual política de expansão, interiorização e democratização dessa modalidade educacional se efetive com qualidade social, produção de conhecimentos, valorização docente e desenvolvimento local, integrado e sustentável (MACHADO, 2011, p. 690).

É importante reconhecermos que um dos maiores problemas na formação do docente no Brasil é a orientação descontextualizada da realidade contemporânea na qual essa formação se desenvolve (ZAMBORLINI, 2007). Essa característica se mostra bastante presente em relação à formação inicial do docente da EPT, já que os profissionais formados nos cursos de bacharel e tecnólogo não tiveram contato com o conteúdo pedagógico necessário para a atuação docente e a temática "Educação Profissional e Tecnológica" não consta na concepção e base curricular dos cursos de licenciatura em Pedagogia no Brasil (BRASIL, 2006a). Já os cursos de licenciatura apresentam um conjunto normativo específico do seu campo disciplinar associado aos saberes da docência ou à formação técnica pedagógica no curso de Pedagogia ou em disciplinas de conhecimentos específicos da área, na qual não 
A valorização do profissional docente no instituto federal de são paulo: aspectos normativos da política

existe a EPT (CARVALHO e SOUZA, 2014). Dessa forma, o modelo atual de formação pedagógica inicial ignora as especificidades do docente da EPT e nos mostra alguns problemas de grande impacto para a sua atuação profissional.

Em decorrência desses apontamentos, pode-se inferir que: existe um espaço aberto na formação inicial dos profissionais que irão atuar na EPT dos institutos federais, sobretudo no IFSP, que inviabiliza a efetivação dessa forma de ensino em pleno acordo com os objetivos dessa proposta educacional; as dificuldades pedagógicas de planejamento, construção e implementação coletiva do currículo são um obstáculo a ser superado; a formação docente continuada, seja ela em cursos livres, cursos de pós-graduação ou capacitação institucional, configura-se em uma necessidade ímpar para promover as discussões, reflexões e o entendimento acerca das possibilidades teóricas, didáticas e pedagógicas da EPT com os profissionais atuantes.

A partir dessas dificuldades em relação à formação docente, verifica-se a necessidade da elaboração e concretização de uma política de formação para os professores que ingressam no Instituto Federal de São Paulo, já que a EPT é pouco estudada e analisada nos cursos superiores de formação inicial de professores. Nesse sentido, para além das necessidades estruturais que esse modelo educacional apresenta, a formação continuada docente se configura como um dos maiores desafios para que existam coerência e coesão de trabalho entre todos os atores envolvidos no desenvolvimento do processo de ensino nas instituições que ofertam a EPT.

A política e as diretrizes para o desenvolvimento de pessoal voltado para a capacitação e qualificação dos professores dos ensinos básico, técnico e tecnológico são regulamentadas pela Portaria $n^{\circ} 2.110 / 13$, que aprova o Programa de Capacitação e Qualificação do IFSP. Esse documento está em conformidade com a política e as diretrizes para o desenvolvimento de pessoal da administração pública federal direta, autárquica e fundacional estabelecida pelo Decreto $\mathrm{n}^{\circ}$ 5.707/06 (BRASIL, 2006b), estabelecendo, em seu artigo $3^{\circ}$, as seguintes finalidades:

I - melhoria da eficiência, eficácia e qualidade dos serviços públicos prestados ao cidadão;

II - desenvolvimento permanente do servidor público;

III - aprimoramento técnico da gestão administrativa do IFSP;

IV - incentivos aos servidores em estabelecerem metas para seu avanço profissional 
HEEREN, M. V.

$$
\begin{aligned}
& \text { e desenvolvimento pessoal; } \\
& \text { V - divulgação e gerenciamento das ações de capacitação; } \\
& \text { VI -- racionalização e efetividade dos gastos com capacitação (BRASIL, 2013). }
\end{aligned}
$$

É importante percebermos que o Decreto $n^{\circ} 5.707 / 06$, por meio do seu artigo $3^{\circ}$, que define as diretrizes da Política Nacional de Desenvolvimento de Pessoal, traz-nos um posicionamento bastante positivo das instituições públicas em relação a essa temática de formação do servidor. Respeitadas essas diretrizes, o IFSP entende que as ações que objetivam a implementação dessa política são reconhecidas como um processo continuado que visa a ampliar conhecimentos, capacidades e habilidades dos servidores, a fim de aprimorar seu desempenho funcional no cumprimento dos objetivos institucionais mediante o desenvolvimento de programas de capacitação ou qualificação, assim definidas no artigo $5^{\circ}$ :

I - Capacitação: processo permanente e deliberado de aprendizagem, que utiliza ações de treinamento e aperfeiçoamento, com o propósito de contribuir para o desenvolvimento de competências institucionais, por meio do desenvolvimento de competências individuais;

II - Qualificação: processo de aprendizagem baseado em educação formal, por meio do qual o servidor adquire conhecimentos e habilidades, tendo em vista o planejamento institucional e o desenvolvimento do servidor na carreira (IFSP, 2013).

No artigo $6^{\circ}$ dessa portaria, é prevista a possibilidade ao servidor de participar do processo, com ou sem afastamento das suas atividades cotidianas, na modalidade "aperfeiçoamento", definida no Programa de Capacitação e "Educação Formal. O Programa de Capacitação pode compreender processos realizados nacional e internacionalmente, sendo considerados, entre outros, eventos, congressos, simpósios, estágios, cursos, cooperação técnica, palestras, workshops, treinamento em serviço etc. Esses processos podem ser requeridos tanto pela instituição quanto pelo servidor, sendo possível a capacitação ser realizada interna ou externamente sem ônus, com ônus limitado ou com ônus à instituição, a depender do caso e dos editais existentes no momento do requerimento. Outra ferramenta importante que fortalece a formação do servidor é a possibilidade que ele possui de afastar-se do exercício do cargo efetivo, no interesse da administração, após cada quinquênio, com a respectiva remuneração por até três meses para participar de ações de capacitação (IFSP, 2013). 
A valorização do profissional docente no instituto federal de são paulo: aspectos normativos da política

Já o programa de qualificação compreende a participação do servidor em cursos de Educação Formal, que abrangem todos os níveis da educação. Nesse contexto, os benefícios oferecidos por esse programa de qualificação podem ser observados por todos os servidores, independentemente da formação apresentada por eles no momento do ingresso no serviço público federal. A Portaria $n^{\circ} 2.110 / 13$ prevê, em seu artigo $n^{\circ} 28$, a possibilidade de o servidor matriculado em cursos de educação fundamental, ensinos médio e superior e pósgraduação lato sensu "requerer o direito de horário especial para servidor estudante, desde que não seja possível conciliar o horário escolar e do setor em que desempenha suas atividades”. Esse benefício também é estendido ao servidor que esteja matriculado em curso de pós-graduação stricto sensu, conforme o artigo 30 da mesma portaria (IFSP, 2013). Adicionalmente, os docentes também podem inserir uma reserva de horas para dedicação ao curso em exercício na carga horária semanal de trabalho na instituição, conforme definiu a Resolução nº 109/15 (IFSP, 2015a).

A resolução que regulamenta a Política de Capacitação e Qualificação do IFSP ainda prevê, em seu artigo $\mathrm{n}^{\circ} 32$, uma modalidade de afastamento para os servidores que estejam matriculados em cursos de pós-graduação stricto sensu. Esse direito do servidor permite que o mesmo se afaste por completo de suas atividades profissionais na instituição, perfazendo, ainda, o recebimento de seus vencimentos integrais pelo período de até dois anos para o servidor que está cursando o mestrado e quatro anos para o que está cursando o doutorado. As vagas oferecidas nesse modelo de incentivo são divulgadas pela reitoria do IFSP a partir de um edital de processo seletivo interno.

É importante ressaltar que os docentes contemplados com esse afastamento remunerado somente poderão gozar desse direito a partir do momento no qual a instituição já tenha contratado um professor substituto para compor as atividades institucionais realizadas pelo servidor em afastamento. Para não comprometer as finalidades da instituição, de acordo com o artigo $3^{\circ}$ do Decreto $\mathrm{n}^{\circ} 7.312 / 10$, que dispõe sobre o banco de professor-equivalente de educação básica, técnica e tecnológica dos institutos federais, a margem de docentes substitutos não pode exceder $20 \%$ do quantitativo de docentes efetivos em cada instituto federal (BRASIL, 2010b). Dessa forma, estabelece-se um limite de vagas para o afastamento remunerado, fazendo que novas vagas para o afastamento surjam somente após o retorno de docentes ao término do curso de pós-graduação. 
A formação docente para atuar na EPT tem sido tema de debates constantes no mundo acadêmico, suscitado questionamentos importantes sobre os saberes profissionais específicos da EPT e qual modelo de formação seria adequado para esse profissional (CARVALHO e SOUZA, 2014). Considerando a heterogeneidade de formação pedagógica e a trajetória profissional dos docentes da educação profissional (MACHADO, 2011), as políticas de formação continuada devem ocupar um espaço de destaque nas instituições de ensino que priorizam uma intensa relação de cooperação entre ação docente, currículo, projetos pedagógicos de cursos e objetivos institucionais.

\subsubsection{Formação continuada docente no IFSP}

É necessário percebermos que a formação continuada dos professores da educação básica brasileira está assegurada no texto da LDB e do Plano Nacional de Educação, configurando-se, dessa forma, em um objeto a ser elaborado mediante uma política pública. A LDB no 9.394/96 apresenta, no artigo 67, § 2, a garantia de valorização do profissional da educação a partir, entre outros, do aperfeiçoamento profissional continuado (BRASIL, 1996). Já o PNE, que estabeleceu um conjunto de 20 metas para serem atendidas nos próximos 10 anos, especificou as metas 15 e 16 para a melhora da formação dos professores da educação básica, bem como a garantia da formação continuada na área de atuação do docente (BRASIL, 2014c). Apesar de a Lei n 11.892/08, de criação dos institutos federais, não prever ou fomentar uma política de formação inicial ou continuada para os docentes da EPT, o IFSP definiu, por meio da Resolução $\mathrm{n}^{\circ}$ 138/2015, um conjunto de normas que orientam a formação continuada para os docentes do IFSP e colocam em prática, de maneira coerente com a LDB e o PNE, ações para a efetivação de uma política pública de formação docente (IFSP, 2015b). Essa resolução apresenta, conforme o artigo $2^{\circ}$, entre outros, os seguintes objetivos:

II - Propiciar a reflexão crítica sobre o fazer pedagógico;

III - Realizar a formação continuada de professores, por meio de encontros e/ou reuniões pedagógicas, abordando questões ligadas à prática docente, também em busca de alternativas frente aos desafios do contexto educativo;

IV - Propiciar estudos de referenciais teóricos e da legislação educacional para subsidiar as ações pedagógicas; 
A valorização do profissional docente no instituto federal de são paulo: aspectos normativos da política

(...)

X - Viabilizar a organização e oferta de encontros, cursos, palestras, oficinas, fóruns, congressos etc., estimulando a participação do professor em ações de formação continuada. (IFSP, 2015b).

Pode-se perceber a preocupação da instituição com o aperfeiçoamento da atividade pedagógica dos docentes, bem como a sua inserção nos contextos educativos específicos de cada unidade de ensino. Dessa forma, é interessante notar que, conforme o item II do artigo $3^{\circ}$, a instituição prevê a formação continuada no local de trabalho docente, condição que facilita e torna mais eficiente a realização da mesma.

Art. $3^{\circ}$ A formação Continuada de Professores no IFSP, considerando sua complexidade e suas múltiplas possibilidades, ocorrerá, principalmente, por meio de:

I. Formação Continuada, realizada pontualmente em atividades internas e externas: cursos, reuniões, encontros, congressos, jornadas, seminários, palestras, oficinas, etc.;

II. Formação Continuada, realizada no câmpus (in loco), por meio de encontros e/ou reuniões pedagógicas periódicas (IFSP, 2015b).

De acordo com o artigo $4^{\circ}$ da Resolução $n^{\circ} 138 / 2015$, e em consonância com a meta 16 do PNE, a instituição concebe o campus como local privilegiado de formação continuada dos professores, "considerando a necessidade de se estabelecer discussões contextualizadas sobre o fazer pedagógico e as dimensões técnica, cultural, científica e extensionista, com base na realidade do campus e nas demandas dos professores (IFSP, 2015b). Dessa forma, para possibilitar essa realidade, o artigo $5^{\circ}$ prevê a designação, em portaria, de uma comissão específica de cada campus responsável pelo planejamento e desenvolvimento das ações de formação continuada.

Art. $5^{\circ}$ Para efetivar as ações de Formação Continuada in loco, será constituída, em cada câmpus, uma equipe de Formação Continuada, composta por, no mínimo, dois e, no máximo, oito servidores.

$\S 3^{\circ}-\mathrm{A}$ equipe de Formação Continuada do câmpus será instituída por meio de Portaria emitida pelo Diretor-Geral, a cada dois anos. Os integrantes poderão continuar compondo a equipe a cada renovação de Portaria (IFSP, 2015b). 
Pode-se observar que a legislação pertinente à formação continuada do IFSP, representada pela Resolução ${ }^{\circ}$ 138/2015, está coerente com os aspectos legais da legislação educacional do Brasil, ou seja, a partir de uma análise dos documentos institucionais, não se verifica inconsistência normativa em relação à possibilidade de formação e capacitação dos docentes da EPT. Ademais, sendo o IFSP constituído como uma autarquia federal, a criação de uma política interna demonstra que a instituição valoriza a ação docente, convalidando, assim, a sua relativa autonomia administrativa, financeira e didática pedagógica prevista em sua lei de criação (BRASIL, 2008).

Esse aspecto se mostra de grande relevância a partir do momento em que consideramos que a capacitação docente, sob os diversos aspectos teóricos relacionados com o fazer profissional, é desenvolvida em situações de proximidade com o campo de atuação docente, já que “[...] noções tão vastas como pedagogia, didática, aprendizagem etc. não têm nenhuma utilidade se não fizermos o esforço de situá-las, isto é, de relacioná-las com as situações concretas do trabalho docente" (TARDIF, 2002, p. 115). A Resolução n 138/2015 se manifesta nesse sentido quando deixa claro, em seu artigo $4^{\circ}$, que o campus é um local de produção de conhecimento e considera a interação entre os sujeitos da aprendizagem um pressuposto inerente a essa produção.

A legislação interna do IFSP prevê a realização de um processo interativo e reflexivo voltado para a resolução de problemas reais com a colaboração mútua entre os sujeitos de um mesmo contexto pedagógico a partir de uma metodologia dinâmica que proporcione açãoreflexão-ação, possibilitando a construção coletiva de novos saberes para a profissão através da abordagem das práxis docente (IFSP, 2015b). Fica evidenciado que a instituição reconhece a lacuna existente nos cursos de formação inicial dos profissionais que atuam na EPT e também defende "a necessidade de se avançar para uma epistemologia da formação com bases na concepção de práxis, que propicia a articulação dialética entre a prática social e seus fundamentos teóricos, históricos, econômicos etc.” (CARVALHO E SOUZA, 2014, p. 887).

Para além dessa análise documental, entretanto, é importante a realização de novos estudos que priorizem a análise sobre a efetivação e o desenvolvimento das ações dessa política de formação continuada pela reitoria da instituição, e também nas unidades de ensino, para maior entendimento acerca da realidade do IFSP em relação à formação inicial dos docentes. Nesse momento, vislumbrando o horizonte da política de formação continuada da Educação Profissional e Tecnológica no IFSP, alguns questionamentos preliminares surgem 
de forma a instigar futuros trabalhos que possibilitem uma reflexão orientadora das ações mais adequadas: diante da realidade de ensino vertical do IFSP e do grande número de temas conflitantes nessa realidade, os pressupostos teóricos e práticos da EPT estão em pauta nos encontros das atividades de formação continuada? O grupo de profissionais de cada campus, docentes ou pedagogos, identificam como necessária uma formação complementar para atuar na EPT? Existe orçamento suficiente para o atendimento das diferentes demandas dos campus? A reitoria do IFSP, por meio da Pró-Reitoria de Ensino (PRE), estabelece alguma prioridade institucional para a formação continuada docente frente à importância dessa forma de ensino inerente à política de educação da rede federal de ensino? A instituição possui informações ou dados estatísticos sobre a formação inicial e necessidades dos docentes que possam orientar o desenvolvimento da formação continuada?

Ainda como forma de instigar novos estudos e ações voltados para a formação continuada do IFSP, é importante ressaltarmos que é possível, dentro do contexto das leis, normas e resoluções sobre a formação continuada no Brasil e dentro da instituição, atender às necessidades para o aperfeiçoamento profissional docente. A organização dos recursos financeiros, humanos e dos espaços de discussão e aprendizagem deve, entretanto, ser pensada e operacionalizada diante da realidade institucional do trabalho docente e das necessidades e possibilidades de desenvolvimento intelectual e humano do estudante inerente à EPT previsto na política nacional de educação.

\subsection{Organização do trabalho docente}

O Instituto Federal de São Paulo apresenta uma estrutura normativa de orientação do trabalho docente que possibilita a sua atuação nos diferentes segmentos educacionais relacionados com os objetivos e finalidades da instituição. Regulamentadas pela Resolução $\mathrm{n}^{\circ} 109 / 15$, as atividades docentes estão divididas em atividades de ensino, pesquisa, extensão, administração e representação e atividades de formação continuada (IFSP, 2015a). Especificamente em relação à formação continuada, é permitido ao docente incluir na sua carga horária semanal de trabalho um período para sua contínua capacitação, condição essa que valoriza a atuação docente na instituição, favorecendo o desenvolvimento das atividades de ensino, pesquisa e extensão propostas pelo IFSP.

Essa resolução definiu, em seu artigo $8^{\circ}$, que a carga horária docente será composta 
por regência de aula, organização do ensino, atividades de apoio ao ensino e complementação de atividades. As atividades de regência do ensino estão previstas no artigo $9^{\circ} \mathrm{com}$ o mínimo de 8 horas e o máximo de 12 horas semanais, podendo, a critério exclusivo do professor, chegar até 16 horas semanais. Essa carga horária é modificada diante do exercício de cargos de direção e coordenação de curso. As atividades de apoio ao ensino perfazem uma carga horária igual à atividade de regência; nesse sentido, um professor que tenha 12 horas semanais de regência de aula terá igualmente 12 horas de atividades de apoio ao ensino. Após a definição da carga horária de regência e apoio ao ensino, o docente deverá distribuir as horas necessárias para completar 40 horas em atividades complementares. Essas atividades deverão compor os projetos de ensino, pesquisa e extensão, bem como atividades de administração, representação e formação continuada.

Essa organização da carga horária do docente no IFSP permite que cada professor possa atuar em benefício do atendimento do tripé institucional compreendido pela interação entre as atividades de ensino, pesquisa e extensão, condição essa que proporciona aos estudantes a possibilidade de vivenciar uma cultura institucional que desenvolva diferentes formas de aprendizagem e produção de conhecimento. A disposição de horas de trabalho específicas para atuação docente em atividades de ensino, pesquisa e extensão permite que o entendimento no qual o trabalho se configura como princípio educativo, a pesquisa como princípio pedagógico e a extensão como ferramenta de interação entre IFSP e a comunidade sejam vislumbrados na prática educacional cotidiana da instituição (IFSP, 2017). Essa característica institucional permite um arranjo específico na atividade dos docentes e estudantes de grande relevância, já que se mostra como um diferencial para a promoção de uma formação humana integral (IFSP, 2017).

Toda a organização do trabalho docente e a definição das disciplinas a serem ministradas, bem como projetos a serem desenvolvidos, iniciam-se no final do semestre letivo anterior, devendo cada docente preencher um Plano Individual de Trabalho Docente (PIT). Ao final do período no qual o PIT é executado, cada docente deverá entregar um Relatório Individual de Trabalho Docente (RIT) acompanhado dos comprovantes e/ou certificados comprobatórios da realização das respectivas atividades. Esses documentos serão avaliados por uma Comissão para Avaliação da Atividade Docente (CAAD) existente em cada campus para sua aprovação, solicitação de adequação ou reprovação. 


\section{Considerações Finais}

Pode-se verificar que existe uma real preocupação do Instituto Federal de São Paulo em qualificar sua atividade educacional a partir de um entendimento no qual os recursos humanos da escola se configuram como elemento principal de uma política educacional, colocando-se como uma instituição que valoriza o servidor docente em relação às suas condições de trabalho, viabilizando-lhe também uma carreira que possibilita seu crescimento tanto sob o aspecto financeiro quanto sob a sua atuação profissional. Ademais, a política interna de capacitação e qualificação do servidor permite que sua atuação possa se expandir e contemplar o tripé institucional de ensino-pesquisa-extensão, favorecendo o adequado desenvolvimento pedagógico dos cursos, contribuindo para que o estudante seja contemplado com uma ação educativa que congregue, em seu cotidiano escolar, as exigências para uma formação integral.

\section{Referências}

BRASIL. Constituição da República Federativa do Brasil de 1988. Brasília, DF, 1988. Disponível em: encurtador.com.br/rBY79. Acesso em: 17 out. 2019.

BRASIL. Decreto $n^{\circ} 5.707$ de 29 de janeiro de 2006. Aprova a Política e as Diretrizes para o Desenvolvimento de Pessoal da administração pública federal direta, autárquica e fundacional. Brasília, DF, 2006b. Disponível em: encurtador.com.br/gqrxG. Acesso em: 17 out. 2019.

BRASIL. Decreto $\mathbf{n}^{\mathbf{0}} \mathbf{7 . 3 1 2}$ de 22 de setembro de 2010. Dispõe sobre o banco de professorequivalente de educação básica, técnica e tecnológica dos Institutos Federais. Brasília, DF, 2010. Disponível em: encurtador.com.br/frvBO. Acesso em: 17 out. 2019.

BRASIL. Lei ${ }^{\circ}$ 9.394, de 20 de dezembro de 1996. Estabelece as diretrizes e bases da educação nacional. Brasília, DF, 1996. Disponível em: encurtador.com.br/npvKZ. Acesso em: 17 out. 2019.

BRASIL. Lei no 11.892, de 29 de dezembro de 2008. Institui a Rede Federal de Educação Profissional, Científica e Tecnológica, cria os Institutos Federais de Educação, Ciência e Tecnologia, e dá outras providências. Brasília, DF, 2008. Disponível em: encurtador.com.br/qsyFT. Acesso em: 17 out. 2019.

BRASIL. Lei $\mathbf{n}^{0}$ 12.772, de 28 de dezembro de 2012. Dispõe sobre a estruturação do Plano de Carreiras e Cargos de Magistério Federal. Brasília, DF, 2012. Disponível em: encurtador.com.br/ejNT1. Acesso em: 17 out. 2019. 
BRASIL. Resolução no 1 , de 15 de maio de 2006. Institui Diretrizes Curriculares Nacionais para o Curso de Graduação em Pedagogia - licenciatura. Brasília, DF, 2006a. Disponível em: encurtador.com.br/sFL37. Acesso em: 17 out. 2019.

BRASIL. Resolução $\mathbf{n}^{\circ}$ 1, de 20 de fevereiro de 2014. Estabelece as diretrizes e os procedimentos para a concessão de Reconhecimento de Saberes e Competências. Brasília, DF, 2014a. Disponível em: encurtador.com.br/fBIY4. Acesso em: 17 out. 2019.

BRASIL. Lei ${ }^{\circ}$ 13.005/2014 de 25 de junho de 2014. Aprova o Plano Nacional de Educação. Brasília, DF, 2014. Disponível em: encurtador.com.br/oxFR4. Acesso em: 17 out. 2019.

CARVALHO, O. F.; SOUZA F. H. M. Formação do Docente da Educação Profissional e Tecnológica no Brasil: Um Diálogo com as Faculdades de Educação e o Curso de Pedagogia. Educ. Soc., Campinas, v. 35, n. 128, p. 883-908, 2014. Disponível em: encurtador.com.br/brCDK. Acesso em: 13 maio 2019.

DEMO, P. Rupturas urgentes em educação. Ensaio: avaliação e políticas públicas em educação. Rio de Janeiro: v. 8, n. 69, dez. 2010. Disponível em: encurtador.com.br/rEMU8. Acesso em: 19 nov. 2020.

IFSP. Resolução $\mathbf{n}^{\circ}$ 109, de 04 de novembro de 2015. Aprova ad referendum alterações no regulamento de atribuições de atividades docentes do IFSP. São Paulo, SP, 2015a. Disponível em: encurtador.com.br/ewET4. Acesso em: 17 out. 2019.

IFSP. Resolução n ${ }^{\circ} 138$, de 08 de dezembro de 2015. Aprova política de formação de professores do IFSP. São Paulo, SP, 2015b. Disponível em: encurtador.com.br/adfLU. Acesso em: 17 out. 2019.

IFSP. Resolução n ${ }^{\circ}$ 163, de 28 de novembro de 2017. Aprova diretrizes para os Cursos Técnicos de Nível Médio na forma integrada ao Ensino Médio do IFSP. São Paulo, SP, 2017. Disponível em: encurtador.com.br/hQUW1. Acesso em: 17 out. 2019.

IFSP. Portaria $\mathbf{n}^{\circ}$ 2.110, de 10 de maio de 2013. Aprova o Programa de Capacitação e Qualificação do IFSP. São Paulo, SP, 2013. Disponível em: encurtador.com.br/hzCW5. Acesso em: 17 out. 2019.

IFSP. Resolução $\mathbf{n}^{\circ}$ 80, de 7 de julho de 2014. Aprova o regulamento para a concessão do Reconhecimento de Saberes e Competências aos docentes pertencentes à Carreira EBTT do IFSP. São Paulo, SP, 2014. Disponível em: encurtador.com.br/guyJP. Acesso em: 17 out. 2019.

MACHADO, L. R. S. O Desafio da Formação dos Professores para a EPT e Proeja. Educ. Soc., Campinas, v. 32, n. 116, p. 689-704, 2011. Disponível em: encurtador.com.br/HMOX3. Acesso em: 15 ago. 2019.

TARDIF, M. Saberes docentes e formação profissional. Petrópolis: Vozes, 2002.

PERES, M. R.; RIBERO, R. C.; RIBEIRO, L. L. P.; COSTA, A. F. R.; ROCHA, V. A formação docente e os desafios da prática reflexiva. Educação. Santa Maria, v. 38, n. 2, p. 289-304. 2013. Disponível em: encurtador.com.br/zJP29. Acesso em: 17 nov. 2020. 
SAVIANI, D. Formação de professores: aspectos históricos e teóricos do problema no contexto brasileiro. Revista Brasileira de Educação. v. 14, n. 40, p. 143-155, São Paulo: 2009. Disponível em: encurtador.com.br/dgiWZ. Acesso em: 14 jul. 2019.

UNESCO. O Perfil dos professores brasileiros: o que fazem, o que pensam, o que almejam / Pesquisa Nacional UNESCO, - São Paulo: Moderna, 2004. Disponível em: encurtador.com.br/mIPS5. Acesso em: 17 nov. 2020.

ZAMBORLINI, M. G. Desenvolvimento profissional de professores: um olhar sobre os professores da educação profissional de nível técnico do Centro Federal de Educação Tecnológica (CEFETES). Revista Capixaba de Ciência e Tecnologia, Vitória, n. 3, p. 20 25, 2007. Disponível em: encurtador.com.br/ahq27. Acesso em: 12 set. 2019.

Recebido em: 17/10/2019

Revisado em: 23/11/2020

Aprovado em: 03/02/2021

Publicado em: 15/06/2021 